\title{
Recent Advances in Kicker Pulser Technology for Linear Induction Accelerators
}

\author{
W.J. DeHope \\ Y J. (Judy) Chen \\ E.G. Cook \\ B.A. Davis \\ B. Yen
}

This paper was prepared for submittal to the

International Pulsed Power Conference

Monterey, CA

June 27-30, 1999

June 1999

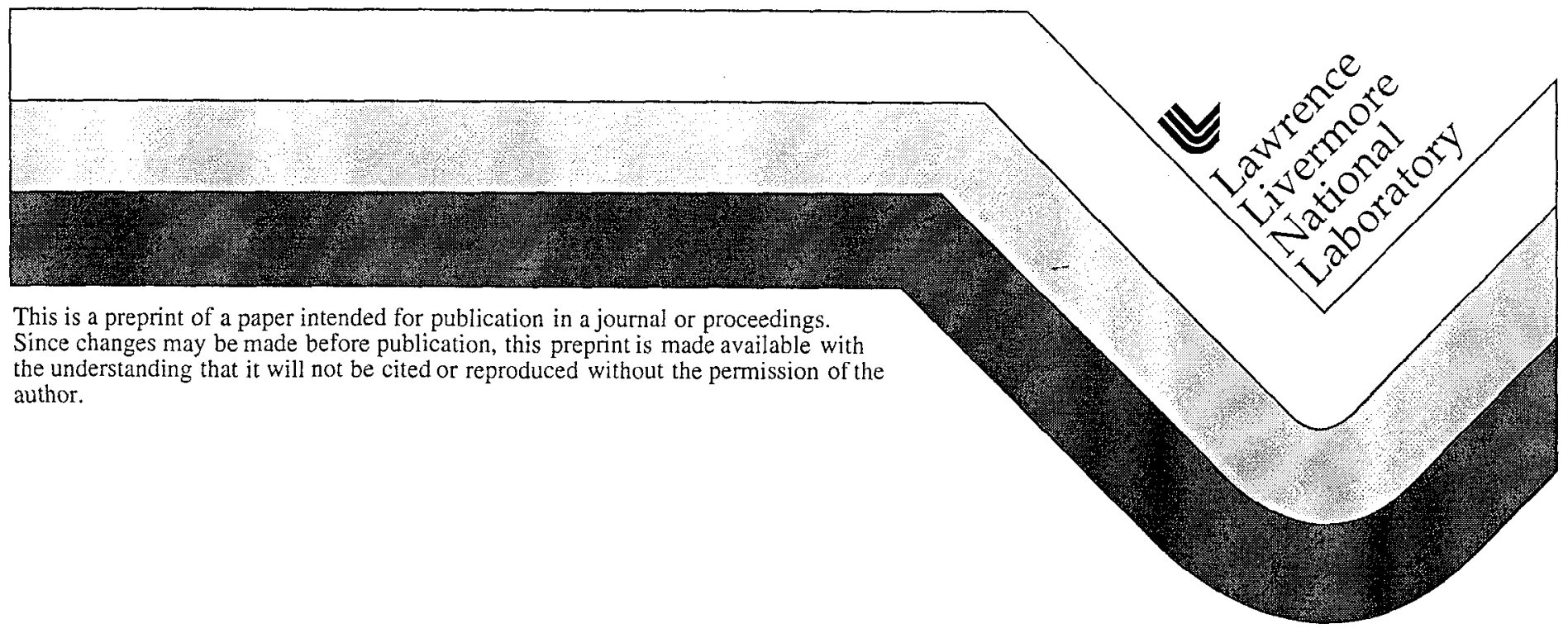




\section{DISCLAIMER}

This document was prepared as an account of work sponsored by an agency of the United States Government. Neither the United States Government nor the University of California nor any of their employees, makes any warranty, express or implied, or assumes any legal liability or responsibility for the accuracy, completeness, or usefulness of any information, apparatus, product, or process

disclosed, or represents that its use would not infringe privately owned rights. Reference herein to any specific commercial product, process, or service by trade name, trademark, manufacturer, or otherwise, does not necessarily constitute or imply its endorsement, recommendation, or favoring by the United States Government or the University of California. The views and opinions of authors expressed herein do not necessarily state or reflect those of the United States Government or the University of California, and shall not be used for advertising or product endorsement purposes. 


\title{
RECENT ADVANCES IN KICKER PULSER TECHNOLOGY FOR LINEAR INDUCTION ACCELERATORS
}

\author{
W. J. DeHope, Y. J. (Judy) Chen, E. G. Cook, B. A. Davis", B. Yen"
}

Lawrence Livermore National Laboratory

PO Box 808, Livermore, CA 94550

\section{Abstract}

Recent progress in the development and understanding of linear induction accelerator have produced machines with 10 's of $\mathrm{MeV}$ of beam energy and multi-kiloampere currents. Near-term machines, such as DARHT-2, are envisioned with microsecond pulselengths. Fast beam kickers, based on cylindrical electromagnetic stripline structures, will permit effective use of these extremely high-energy beams in an increasing number of applications. In one application, radiography, kickers are an essential element in resolving temporal evolution of hydrodynamic events by cleaving out individual pulses from long, microsecond beams. Advanced schemes are envisioned where these individual pulses are redirected through varying length beam lines and suitably recombined for stereographic imaging or tomographic reconstruction.

Recent advances in fast kickers and their pulsed power technology are described. Kicker pulsers based on both planar triode and all solid-state componentry are discussed and future development plans are presented.

\section{Introduction}

Although direct application of Faraday's Induction Law as a means to accelerate particles in a circular orbit in a changing magnetic field [1] was utilized early in the history of accelerators, the technique was not successfully applied to linear acceleration until the mid 1960's. Advances in pulsed power technology have enabled this technology to steadily develop. Modern induction linacs find application [2] in fields such as heavy ion fusion, advanced radiography, and advanced rf sources for nextgeneration linear colliders.

Stanley Livingston [3] began the practice in the late 1950 's of plotting peak particle accelerated energy as a function of time as accelerator technology matured. Such Livingston Charts have been extended [4] by modern researchers. Using more appropriate figures of merit for induction linacs, an analogous graph of either beam power or beam energy per pulse can be generated. As a function of the year in which the machine came on line, Fig. 1 plots points for Astron [5], ERA [6], FXR [7], ATA [8], ETA-II [9], FXR-Upgrade [10], DARHT single axis [11], and DARHT-II [12]. Although a significant degree of spread exists among these special-purpose machines, a general trend of doubling every 6-7 years seems apparent.

Fast beam kickers and the pulsed power technology to drive them are an enabling technology in the full utilization of induction linac power, particularly for advanced radiography applications.

\footnotetext{
${ }^{*}$ Bechtel Nevada, DoE/LLNL, Livermore, CA 94550
}

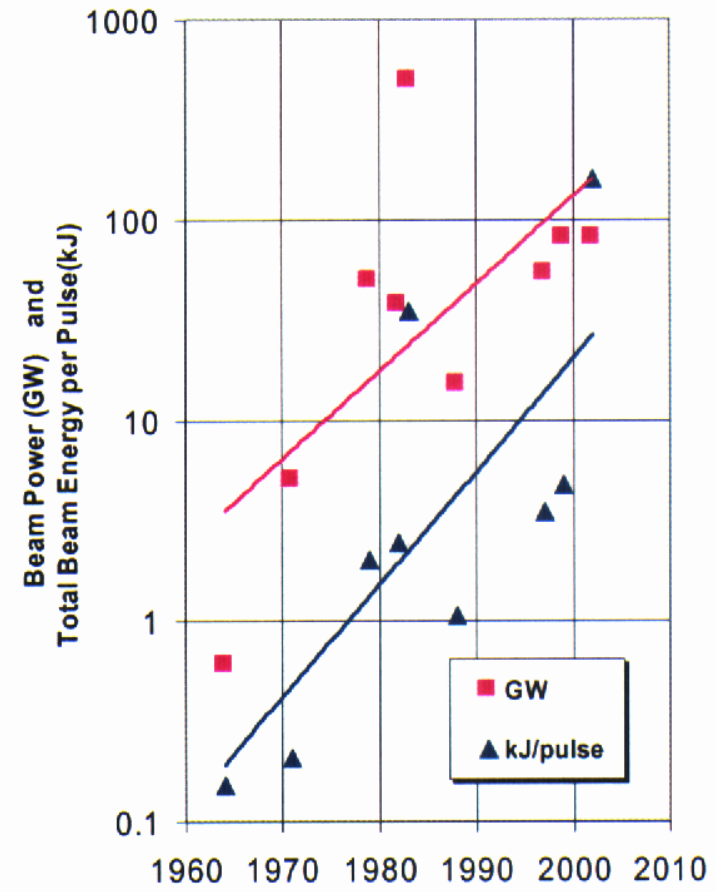

Figure 1. Beam power in GW and beam energy per pulse in $\mathrm{kJ}$ plotted vs. time for induction linacs.

\section{Kicker Requirements}

Kicker technology has evolved [13-16] to a topology similar to stripline-based beam position monitors (Fig. 2). Kickers have demonstrated the ability [17] to control beam direction on nano-second time scales.

Kickers for radiography applications are being developed (Fig. 3) in the 10-15 kV, 200-300 A range that present a 50-ohm load to the pulser. Pulse widths from 20-200 ns are nominal. Although the overall e-beam rise and fall time is also a function of the kicker's "fill time", fast rise and fall times from the kicker pulsers is critical to ensure a minimum of beam interception within the accelerator structure. A $10-90 \%$ specification for pulser rise and fall time that is currently in use is $10 \mathrm{~ns}$.

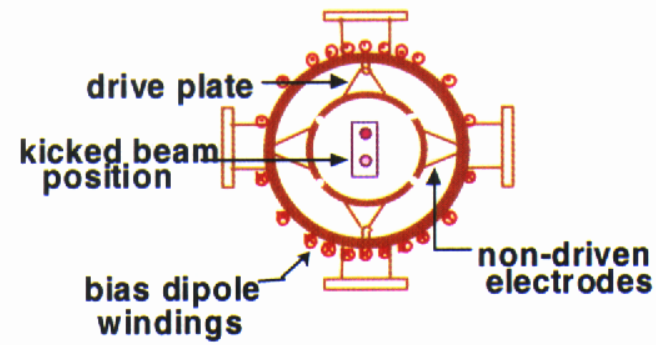

Figure 2. Schematic of stripline kicker with coaxial feeds and $\mathrm{dc}$ bias windings. 


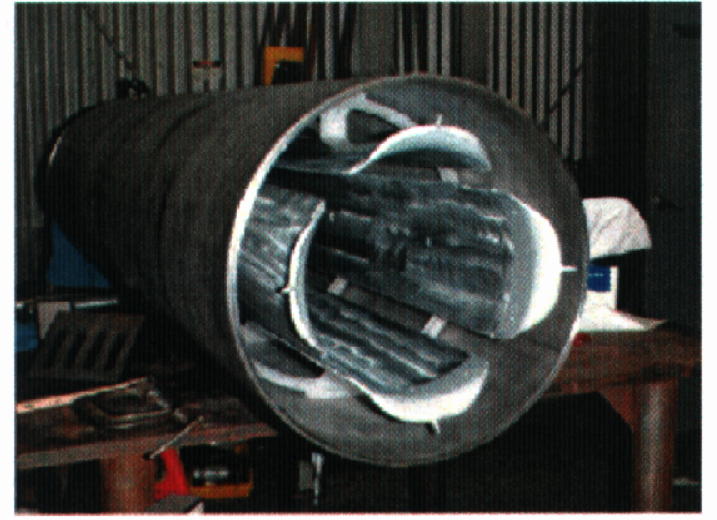

Figure 3. ETA-II kicker viewed with ends and coaxial connections removed..

\section{Kicker Pulser Development}

Fast pulsers have previously been developed [18-20] in conjunction with the ATA program to support both an Injection Current Modulation scheme and a Fast Correction Coil scheme to correct for time-dependent beam transverse motion effects such as corkscrew motion. Both approaches were based on Eimac YU-114 planar triode pairs in cascode with a fast DEI FET. The FET was driven by a wideband op-amp followed by an $\mathrm{rf}$ transistor in an emitter follower configuration. This basic circuit (Fig. 4) was packaged on a 45-degree wedgeshaped sector. The outputs from 8 such sectors were paralled and output to a 50-ohm coax. These compact units (Fig. 5) have been adapted to ETA-II kicker experiments and have proven a reliable kicker pulser..

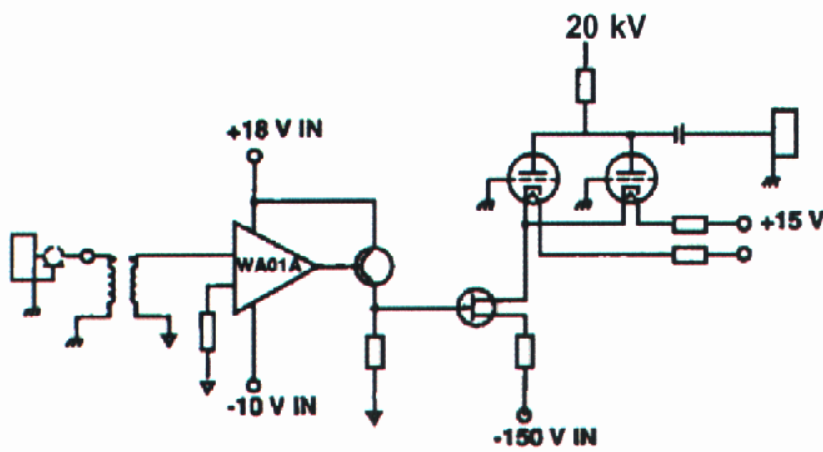

Figure 4. Simplified schematic of a single sector of the FET and planar-triode based fast pulser design.

In an effort to extend the linearity of these pulsers, a new design [21] based on two stages of planar triodes was implemented. The output stage is based on Eimac Y820 's, the production version of the YU-114. The intermediate stage is based on developmental YU-176 tubes. A diagram of $1 / 3$ of the final circuit is shown in Figure 6. The tubes of both stages are operated in grounded cathode configuration and a semi-rigid coaxbased transmission line transformer is utilized for impedance matching. The design also takes advantage of fast linear hybrid microcircuit technology developed for high-resolution, large CRT displays. This linear hybrid is

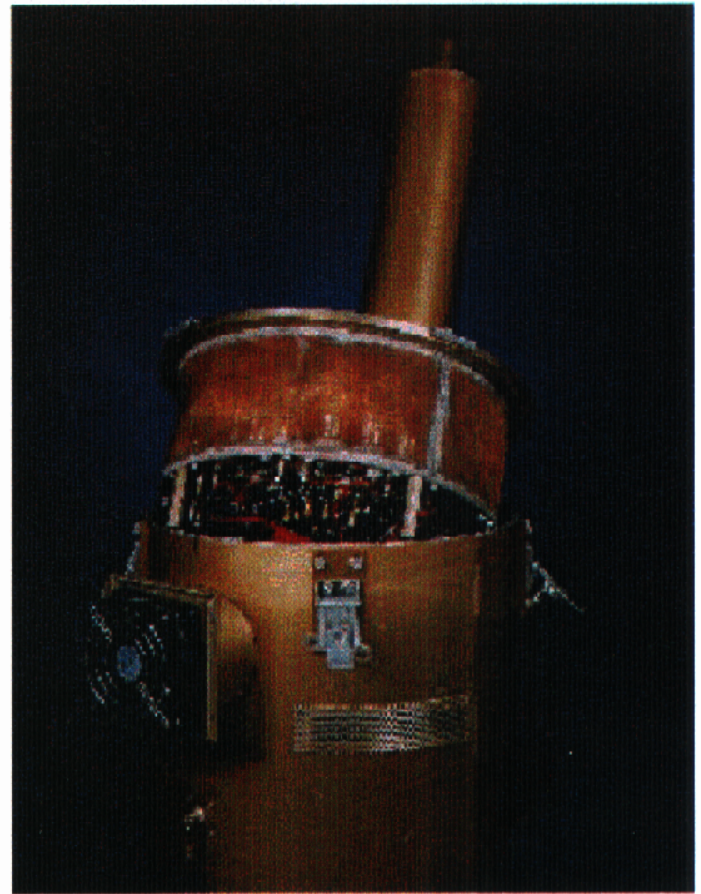

Figure 5. Photograph of the compact FET and planartriode based fast pulser design.

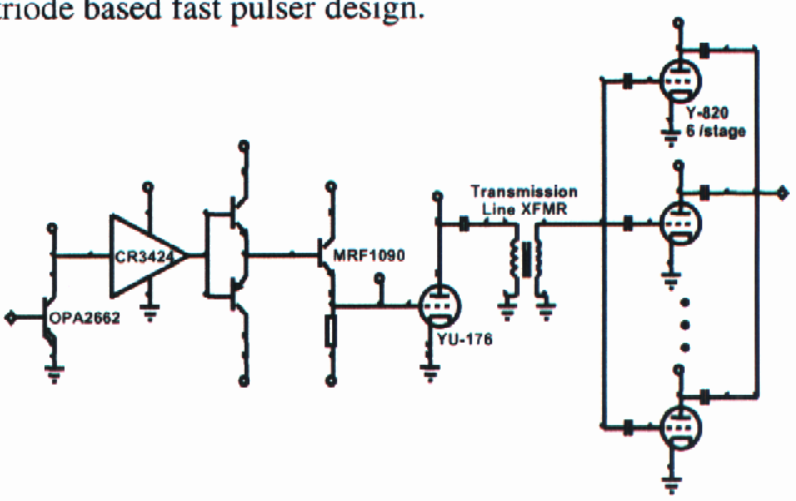

Figure 6. Simplified schematic of new planar triodebased kicker pulser with improved linearity.

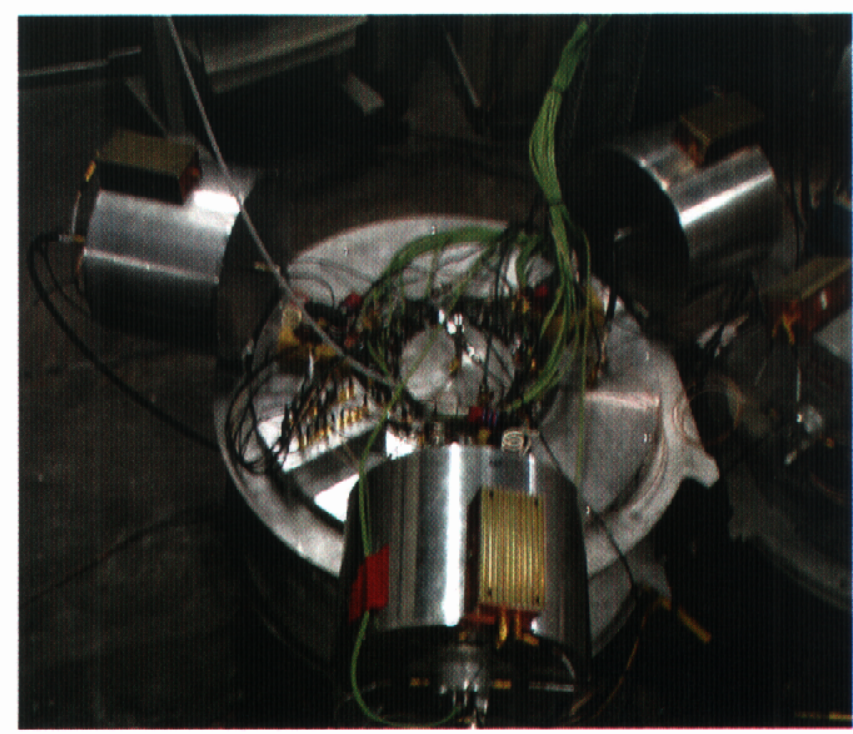

Figure 7. Photograph of improved-linearity kicker pulser. 
driven by an operational transconductance amplifier to form the bulk of the input stage. This completed design (Fig. 7) has recently proven to be stable over a wide dynamic range (Fig. 8) and capable of high bandwidth amplitude modulation (Fig. 9).

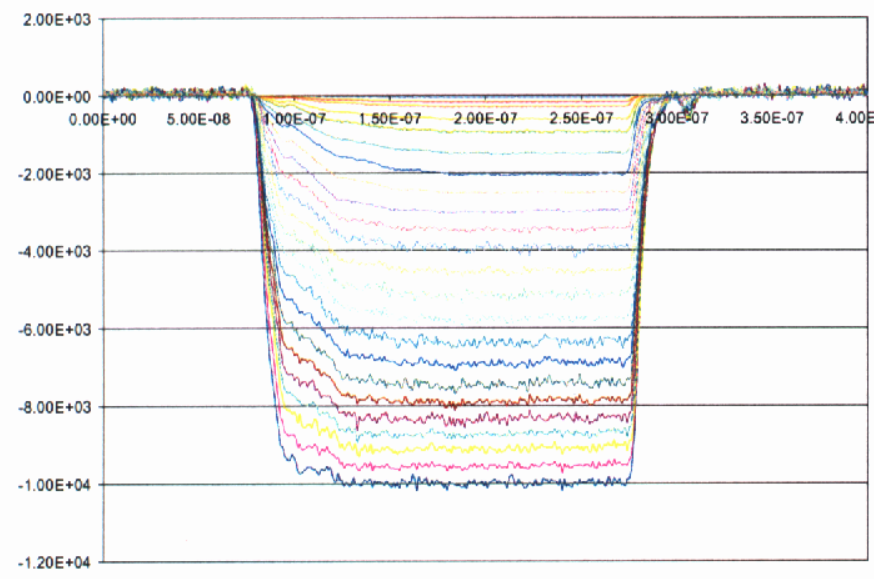

Figure 8. Overlaid 200-ns output pulses for varying drive levels to the FET-free kicker pulser.

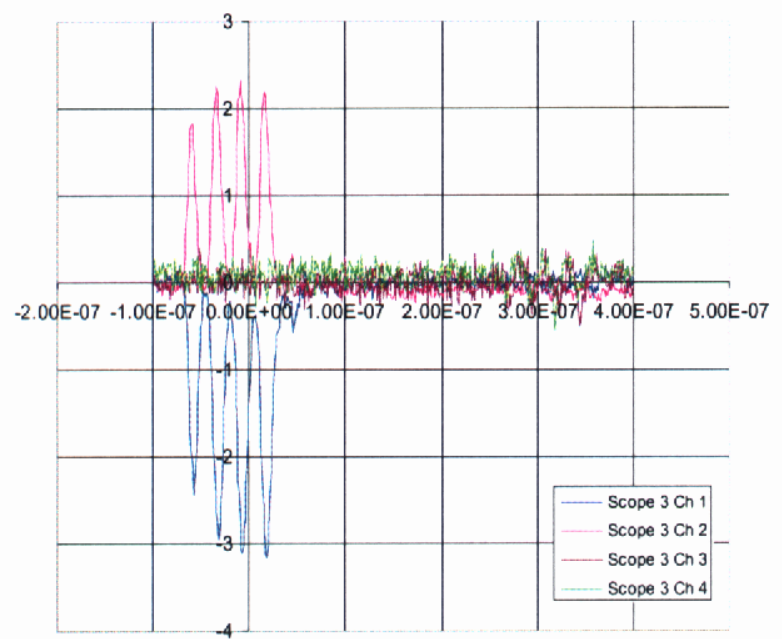

Figure 9. $100 \%$ modulation at $40 \mathrm{MHz}$ from the FET-free kicker pulser.

\section{Ongoing Work}

In recent years, the supply of high-frequency planar triodes has become increasingly uncertain. Particularly when designing for accelerators with an anticipated lifetime measured in decades, it seemed necessary to develop an all solid-state kicker pulser design. Based on the ARM-II modulator technology (Fig. 10) the new pulser will be comprised of multiple, stacked modulators based on Metglas cores whose output is inductively added on a voltage-summing center stalk (Fig. 11). Each stacked cell must be capable of full-current operation and so is comprised of multiple FETs. This manifold parallelling of FETs has been successfully demonstrated on ARM-II [22]. The FET gates are efficiently driven by a Silconix totem-pole driver chip. Initial tests with ST FETs (STW5NB100) have been encouraging (Fig. 12). Newer devices from IXSYS and APT promise enhanced performance. Analog control to the $\pm 10 \%$ level felt necessary will be provided by $2-4$ stacks of analog modules, presently envisioned as "voltage subtractors" and utilizing FETs biased in their linear region.

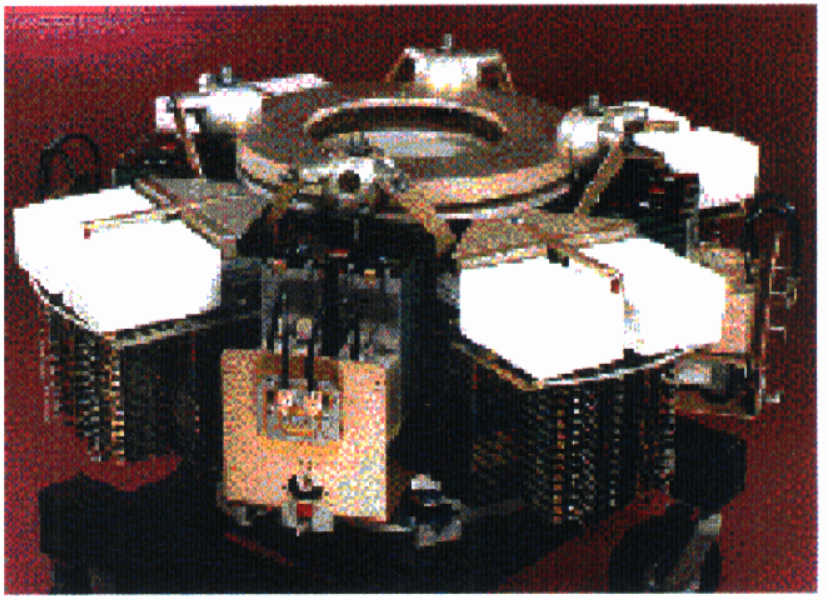

Figure 10. ARM-II inductive adder implementation.

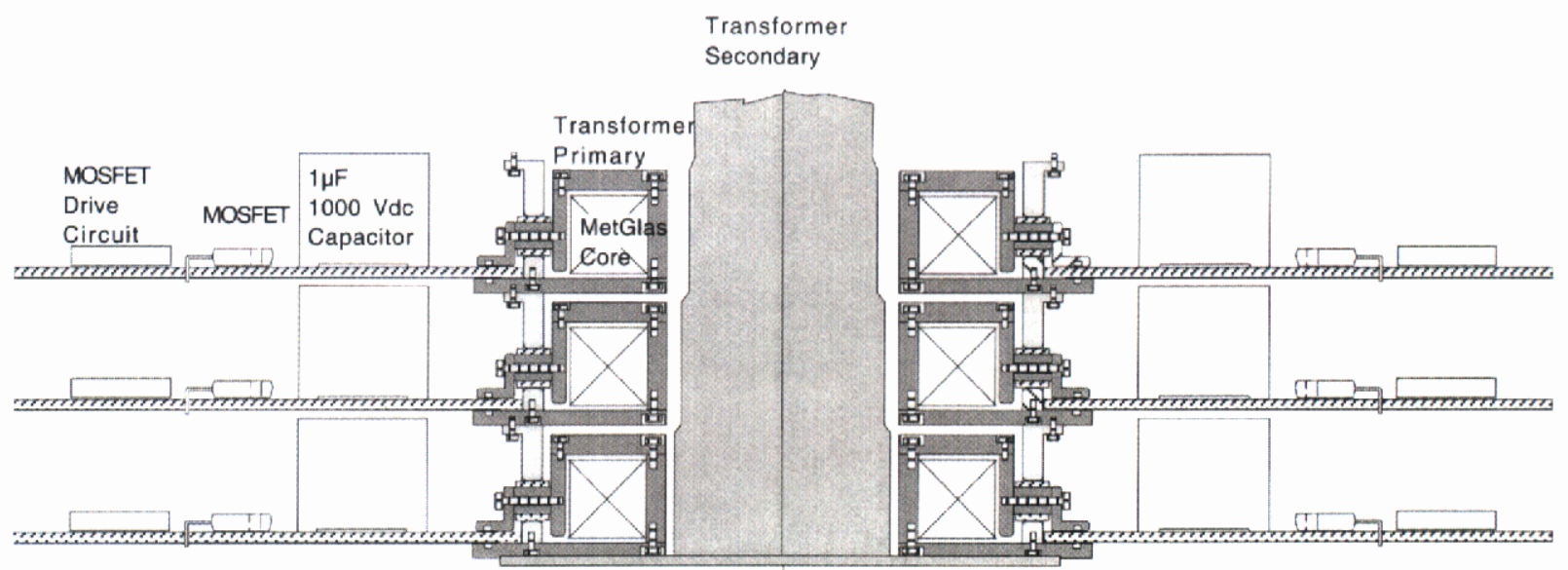

Figure 11. Cross-section of stacked modules making up an all solid state kicker pulser based on ARM-II technology. 


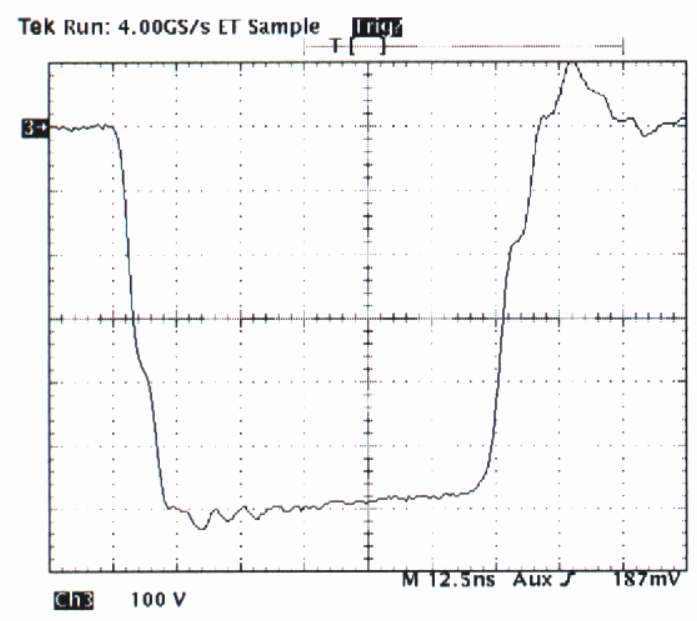

Figure 12. Pulsed response of fast FETs envisioned for all solid-state kicker pulsers.

We are also implementing a control algorithm (Fig. 13) to correct for non-linearities in the pulsers and for cable dispersion effects.

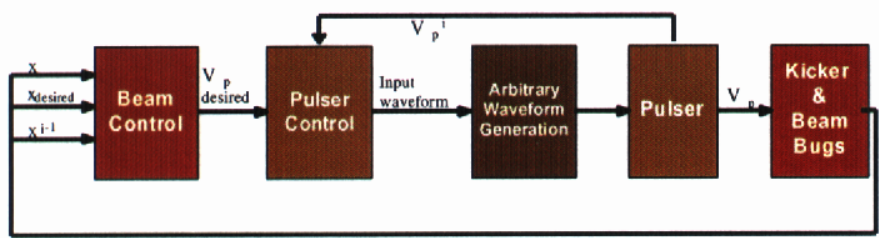

Figure 13. Flow diagram of pulser control logic for integrated beam/pulser control.

\section{Acknowledgement}

This work was performed under the auspices of the US DoE by LLNL under contract no. W-7405-Eng-48

\section{References}

[1] D. W. Kerst, "The Acceleration of Electrons by Magnetic Induction", Phys. Rev. 60, 47-53, (1941)

[2] S Yu, "Review of New Developments in the Field of Induction Accelerators" $28^{\text {th }}$ Intl. Linac Conf., August 26-30, 1996, Geneva, Switzerland, http://www.cern.ch/CERN/Divisions/PS/Linac96/

[3] M. S. Livingston and J. P Blewett, Particle Accelerators, McGraw Hill, 1962, p. 6

[4] P. J. Bryant and Kjell Johnsen, The Principles of Circular Accelerators and Storage Rings, Cambridge University Press, 1993, page 2

[5] N. C. Christofilos, et al, "High Current Linear Induction Accelerator for Electrons", Rev. Sci. Inst. 35, No. 7, 886-890 (1964)

[6] R. T. Avery, et al, "The ERA $4 \mathrm{MeV}$ Injector", 1971 Part. Accel. Conf., Chicago IL, IEEE Trans. Nucl Sci, NS-18, No. 3, 479 (1971)

[7] B. Kulke, et al, "Initial Performance Parameters on FXR", in Proc IEEE $15^{\text {th }}$ Power Modulator Symposium, Baltimore, MD, June, 1982
[8] R. J. Briggs, "High Current Electron Linacs" in Proc. of the 1984 Linear Accel. Conf.

[9] J. C. Clark, et al, "Design and Initial Operation of ETA-II Induction Accelerator", in Proc. Of the 1988 Linear Accel. Conf., Williamsburg, VA, Oct 3-7, 1988

[10] R. D. Scarpetti, et al, "Upgrades to the LLNL Flash $\mathrm{X}$-ray Induction Linear Accelerator (FXR)", $11^{\text {th }}$ IEEE Intl. Pulsed Power Conf., Baltimore, MD, June 29-July 2, 1997

[11] M. J. Burns, et al, "DARHT Acclelerators Update and Plans for Initial Operation", 1999 Part. Accel. Conf., New York City, Mar. 29th - April 2nd, 1999 http://pac99.bnl.gov/Pac99/Program/PMenu.html

[12] T. L. Houck, et al, "Physics Design of the DARHT $2^{\text {nd }}$ Axis Accelerator Cell", $19^{\text {th }}$ International LINAC Conf., Chicago, IL, August 23-28, 1998, http://www.aps.anl.gov/conferences/LINAC98/pap ers/TH4040.pdf

[13] D. Bohm and L. Foldy, "The Theory of the Synchrotron" Phys. Rev. 70, 249-258 (1946)

[14] R. T. Avery, A. Faltens, E. C. Hartwig, "NonIntercepting Monitor of Beam Current and Position", 1971 Part. Accel. Conf., Chicago IL, IEEE Trans. Nucl Sci, NS-18, No. 3, 920 (1971)

[15] K.-Y. Ng, "Impedances of Stripline Beam-Position Monitors", Part. Accels, 프, 93-102, (1988)

[16] G. J. Caporaso, et al, "Transmission Line Analysis of Beam Deflection in a BPM Stripline Kicker", 1997 Part. Accel. Conf., Vancouver, April 12-16, 1997, http://www.triumf.ca/pac97/papers/

[17] Y. J. Chen, "Precision Fast Kickers for KiloAmpere Electron Beams" 1999 Part. Accel. Conf., New York City, NY, March 29th - April 2nd, 1999, http://ftp.pac99.bnl.gov/Papers/Wpac/FRAR5.pdf

[18] K. Whitham, et al, "Fast Correction Coils for Linear Induction Accelerators", $7^{\text {th }}$ IEEE Pulsed Power Conf., Monterey, CA, June 12-14, 1989

[19] E. E. Bowles, W. C. Turner, "A 50-MHz, 12-MW Induction Linac Current Modulator", $7^{\text {th }}$ IEEE Pulsed Power Conf., Monterey, CA, June 12-14, 1989

[20] E. E. Bowles, W. C. Turner, "Induction Linac Energy Regulation via Injector Current Modulation", $199019^{\text {th }} \quad$ Power Modulator Symposium, San Diego, CA, June 26-28, 1990

[21] R. Buckles, B. Davis, B. Yen, "A Linear Hybrid Kicker Modulator for ETA-II", $11^{\text {th }}$ IEEE Intl. Pulsed Power Conf., Baltimore, MD, June 29-July 2, 1997

[22] H. Kirbie, et al, "MHz Repetition Rate Solid-State Driver for High Current Induction Accelerators", 1999 Part. Accel. Conf., New York City, Mar. 29April 2, 1999, http://ftp.pac99.bnl.gov/Papers/ 